\title{
Article \\ Evaluation of Different Internal Designs of Hydraulic Nozzles under an Accelerated Wear Test
}

\author{
Marek Milanowski ${ }^{1, *(D)}$, Alaa Subr ${ }^{2}$ and Stanisław Parafiniuk ${ }^{3}(\mathbb{D}$ \\ 1 Department of Thermal Technology and Food Process Engineering, Faculty of Production Engineering, \\ University of Life Sciences in Lublin, Głęboka 31, 20-612 Lublin, Poland \\ 2 Department of Agricultural Machines and Equipment, College of Agricultural Engineering Sciences, \\ University of Baghdad, Baghdad, Al-Jadiriya 10071, Iraq; alaa.kamel@coagri.uobaghdad.edu.iq \\ 3 Department of Machinery Exploitation and Management of Production Processes, Faculty of Production \\ Engineering, University of Life Sciences in Lublin, Głęboka 31, 20-612 Lublin, Poland; \\ stanislaw.parafiniuk@up.lublin.pl \\ * Correspondence: marek.milanowski@up.lublin.pl
}

check for updates

Citation: Milanowski, M.; Subr, A.; Parafiniuk, S. Evaluation of Different Internal Designs of Hydraulic

Nozzles under an Accelerated Wear Test. Appl. Sci. 2022, 12, 889. https:// doi.org/10.3390/app12020889

Academic Editor:

Roberto Romaniello

Received: 13 December 2021

Accepted: 13 January 2022

Published: 16 January 2022

Publisher's Note: MDPI stays neutral with regard to jurisdictional claims in published maps and institutional affiliations.

Copyright: (C) 2022 by the authors. Licensee MDPI, Basel, Switzerland. This article is an open access article distributed under the terms and conditions of the Creative Commons Attribution (CC BY) license (https:// creativecommons.org/licenses/by/ $4.0 /)$.

\begin{abstract}
The use of worn-out agricultural nozzles in pesticide application has a negative effect on the efficiency and cost of the application process. It also has an effect on environmental pollution due to an excessive amount of pesticide being applied when spraying with worn-out nozzles. In this paper, the resistance to wear of three different internal design hydraulic nozzles was ascertained. Changes in the flow rate and spray distribution as a result of this wear were also investigated. The wear test was done inside a closed system, and it was accelerated using an abrasive material to generate $100 \mathrm{~h}$ of wear. The tested nozzles were the Turbo TeeJet (TT)-twin chambered, Turbo Twinjet (TTj60)-dual outlet, and Drift Guard (DG)-pre-orifice. Wear rate, flow rate, and the virtual coefficient of variation $\left(\mathrm{CV}_{\mathrm{v}}\right)$ were measured at different wear intervals. The results showed that the TTj60 type was the most resistant to wear, followed by the TT type and DG. The latter two types showed an increase in the flow rate only in the first $45 \mathrm{~h}$ of wear. Virtual coefficient of variation $\left(\mathrm{CV}_{\mathrm{V}}\right)$ values were less than $10 \%$ after finishing the test (after $100 \mathrm{~h}$ of wear) for the three types of nozzles, which are acceptable values according to International Organization for Standardization (ISO) 16122-2, 2015.
\end{abstract}

Keywords: wear rate; flow rate; spray distribution CV; nozzle internal design

\section{Introduction}

Different designs of nozzles have been introduced with the aim of reducing drift (by producing a larger drop size) or enhancing the spray coverage. This included, as compared with standard flat fan nozzles, changing the internal design, changing the producing method of the spray fan, as well as changing the number of fans for single nozzles. The geometrical design of the nozzle has an effect on the nozzle efficiency [1]. Miller et al. [2] concluded that nozzle performance depends on its design, the spray pressure, and the liquid properties. Pre-orifice nozzles were developed to reduce drift by decreasing the internal pressure inside the nozzle, hence decreasing the exit pressure. This decrease in pressure results in a reduction in the number of small drops in the spray, which in turn will affect the coverage percentage [3]. Lafferty and Tian [4] concluded that to increase the drop size, the turbulence intensity must increase, while exit velocities must decrease. The former is also responsible for diminishing the atomization energy of the spray. The pre-orifice design probably has higher internal velocity, but this is accompanied by higher turbulent intensity and this results in a higher loss in energy. Moreover, the increase in turbulence due to the upstream orifices results in a decrease in the pressure and then in spray exit velocity.

The spraying nozzles are the main part of the sprayers; they can affect the uniformity of the spray application [5], droplet size [6], deposition of spray [7], and the yield [8]. The 
wear of a spraying nozzle due to the usage life could affect its performance [9]. Using worn nozzles can be costly to farmers when applying pesticide products, and the price of replacing a worn nozzle could be much less than spraying incorrectly. The factors that affect the wear of nozzles are nozzle type, size, material of fabrication, shape of orifice, as well as operating pressure and the usage time. The test of nozzle wear is also affected by many factors, including the test duration, type and concentration of the abrasive material, and the duration of using this material before the nozzle must be replaced. It should be noted that the wear of the nozzle could affect the flow rate, drop size of the spray, and the spray pattern distribution [10].

The results of the study of Forney et al. [11] showed that a significant error could happen to the spray distribution measurement if small variations occur in the nozzle operation conditions (for example, pressure or flow rate), and these errors cannot be detected by a test of spray distribution (using a patternator).

The scanning electron microscopic study of Krishnan et al. [12] indicates that nozzle wear patterns could be noticed by comparing micrographs of new and worn nozzles. Moreover, they found that brass and plastic nozzles wear faster than nickel-coated brass and stainless steel nozzles. Singh and Bhatt [13] also saw that plastic nozzles had the highest wear rate when compared with ceramic and stainless steel nozzles. Moreover, they reported that the wear rate varied approximately with the square root of the use time.

The wear rate of nozzles can be described using a system of mathematical equations for the prediction of hollow-cone nozzle wear. This system depends on the flow rate of nozzles as an indicator of the wear rate and also includes physical parameters (one being the accelerated wear test) for nozzles made of different materials. Results reveal that the developed system could be applied to predict wear rates, since experimental and calculated values were strongly related [14].

Bochniak et al. [15] studied the difference between new and worn nozzles by examining the distribution and size of stains of using non-parametric bootstrap confidence intervals. Sayinci [16] recommended applying the elliptic Fourier analysis (EFA) method to study the wear of the nozzles since this method succeeded in distinguishing shape differences among flat fan nozzle orifices directly after production. Kluza et al. [17] concluded that the mathematical model that they developed could be used to determine the wear degree of the nozzles depending on the spray distribution produced from those nozzles.

According to Sayinci [18], as nozzles start to wear, their orifices will increase in size and this will enhance the minimum flow rate required for the complete atomization of the spray. However, this increase in the flow rate (if the sprayer pump will provide it) will decrease the minimum spray pressure required for the nozzles.

In work of Matthews [19], the main specifications applied to evaluate nozzle condition were the flow rate and the spray volumetric distribution, and then a laser technique was introduced to measure the drop size of the spray. As operating pressure affects the flow rate and the life of the nozzle (the orifice dimensions), in this study, it is used as an indicator for nozzle performance.

Nozzle wear can affect the nozzle performance with time, leading to a change in the produced spray characteristics. According to the literature, this wear is a function of different factors. However, the effect of the wear on the nozzles when they have the same nominal flow rate, but are made with a different internal design, is unknown.

In our work, to understand this form of wear effect, nozzles of different internal design (from the same material and manufacturer) were chosen, namely, pre-orifice, twin orifice, and twin chamber nozzles types. The objectives of this study were, firstly, to compare and evaluate the wear behavior of different internal design nozzles, and, secondly, to determine the changes in the main performance parameters of those nozzles after they had been subjected to the accelerated wear test. 


\section{Materials and Methods}

\subsection{Nozzle Characteristics}

All of the tested nozzles were made of the same material, which is polymer; they have the same nominal flow rate $(1.18 \mathrm{~L} / \mathrm{min})$ and spray angle $\left(110^{\circ}\right)$ at 3.0 bar pressure, but they have a different internal design (Table 1).

Table 1. Features of the nozzles used in the study *

\begin{tabular}{|c|c|c|c|c|c|c|}
\hline $\begin{array}{l}\text { Nozzle Type } \\
\text { and Size }\end{array}$ & Full Name & $\begin{array}{l}\text { Nominal Flow } \\
\text { Rate, L/ min }\end{array}$ & Spray Angle, ${ }^{\circ}$ & $\begin{array}{c}\text { Pressure } \\
\text { Range, Bar }\end{array}$ & Design Feature & $\begin{array}{c}\text { Application } \\
\text { Rate, } 1 \mathrm{ha}^{-1} \text { (at } \\
\text { Speed of } \\
4 \mathrm{~km} \mathrm{~h}^{-1} \text { ) }\end{array}$ \\
\hline TeeJet TT 03 & $\begin{array}{c}\text { Turbo TeeJet, } \\
\text { Wide Angle Flat } \\
\text { Spray }\end{array}$ & 1.18 & 110 & $1.0-6.0$ & $\begin{array}{l}\text { Twin chamber, } \\
\text { large and } \\
\text { rounded } \\
\text { internal } \\
\text { passage }\end{array}$ & 354 \\
\hline TeeJet TTj60 03 & $\begin{array}{c}\text { Turbo Twinjet, } \\
\text { Twin ** Flat } \\
\text { Spray }\end{array}$ & 1.18 & 110 & $1.5-6.0$ & $\begin{array}{l}\text { Dual outlet } \\
\text { produces dual } \\
110^{\circ} \text { flat fan } \\
\text { spray patterns }\end{array}$ & 354 \\
\hline TeeJet DG 03 & $\begin{array}{c}\text { Drift Guard Flat } \\
\text { Spray }\end{array}$ & 1.18 & 110 & $2.0-5.0$ & $\begin{array}{l}\text { Removable } \\
\text { pre-orifice }\end{array}$ & 354 \\
\hline
\end{tabular}

Nozzles TT, TTj60, and DG have a pre-orifice design (Figure 1), the intention being mainly to minimalize drift (low-drift nozzles) by producing drops of coarse drop size and by reducing the percentage of fine drops inside the spray spectrum. This is done by reducing the liquid velocity and the internal pressure before the final orifice of the nozzle tip. For example, the TT and TTj60 nozzles have the same internal design, but with one difference: The TTj60 has dual spray fans compared to one spray fan for the TT.

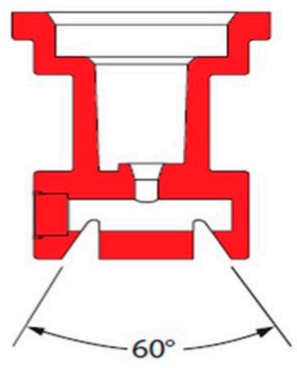

a)

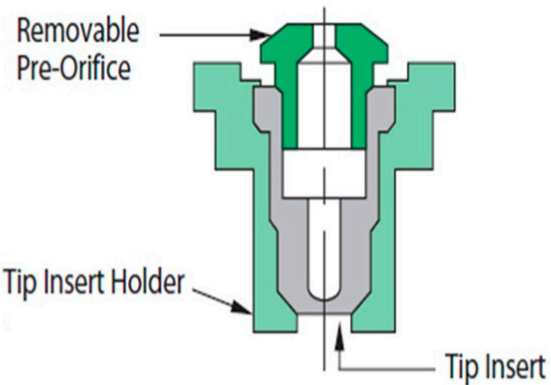

b)

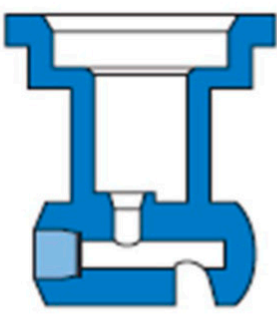

c)

Figure 1. Cross-section view of the tested nozzles: (a) TTj60, (b) DG, (c) TT (Teejet products, Spraying Systems Co., Illinois USA).

Samples consisted of the purchase of twelve nozzles from each type; six nozzles were then selected randomly from the sample and were subjected to the accelerated wear test.

\subsection{The Wear Test and Flow Rate Measurement}

The accelerated wear test was undertaken, according to the ASAE S471 [20] standard, inside a device (Figure 2) that was built for this purpose. The device consisted of a $1000 \mathrm{~L}$ tank with a closed system to circulate the abrasive material $(18.2 \mathrm{~kg}$ Kaolin $\mathrm{KOM}+300 \mathrm{~L}$ water). The nozzles were subjected to $100 \mathrm{~h}$ of accelerated wear testing. Measurements of 
flow rate were done after every fifth hour during the wear cycle. Measurement of spray distribution occurred after every $10 \mathrm{~h}$ of wear testing.

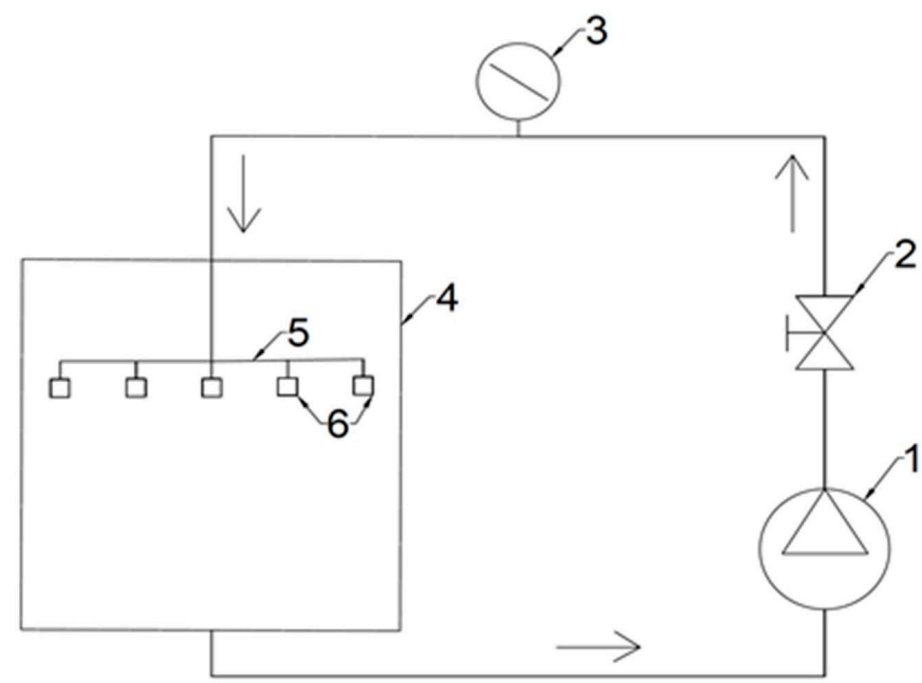

Figure 2. Schematic diagram of the accelerated wear test device: 1 -pump, 2-pressure regulator, 3-pressure gauge, 4-tank, 5-nozzle holder, 6-nozzles.

After each wear interval, the flow rate measurements were done using a specific measuring device from ITEQ, Wallonia-Belgium. This device assesses the flow rate (quantity of water sprayed in specific time) for multi-nozzles after detaching them from the sprayer boom [21]. Tap water with a $21^{\circ} \mathrm{C}$ temperature and at 3.0 bar pressure was used. The measurement for every nozzle of the six nozzle samples was replicated three times. The value for the flow rate after a specific wear interval and for a specific nozzle type was reported as an average for those six nozzles and replications.

The wear rate, which represents the percentage increase in the flow rate compared with the nominal flow rate of new nozzles, was calculated from the following formula [22]:

$$
u_{i}=\left|\frac{q_{i}-Q_{\text {nom }}}{Q_{\text {nom }}}\right| \times 100 \%
$$

where:

$u_{i}$-wear rate of the $\mathrm{i}^{\text {th }}$ nozzle, $\%$;

$q_{i}$-measured flow rate of the $\mathrm{i}^{\text {th }}$ nozzle, $\mathrm{L} / \mathrm{min}$;

$Q_{\text {nom }}$-nominal flow rate, $\mathrm{L} / \mathrm{min}$.

\subsection{Spray Distribution}

Spray distribution (or transverse distribution) is a measurement of the quantity of water that is accumulated within a certain time in each specific position under the spray pattern. The homogeneity of the spray distribution of the certain nozzles was also tested and assessed by ascertaining the coefficient of variation $(\mathrm{CV})$. In undertaking this, the $\mathrm{CV}$ of each nozzle type was calculated after a specific wear interval. The coefficient of variation (CV) was calculated as follows [23]:

$$
\mathrm{CV}=\frac{\mathrm{s}}{\overline{\mathrm{x}}} \times 100 \%
$$

where:

$\mathrm{CV}$-coefficient of variation, \%;

$S$-standard deviation of the collected spray volumes;

$\overline{\mathrm{x}}$-mean spray volumes accumulated in the full overlapping sector. 
If the spray was evenly distributed, then the CV value would be equal or near to zero; were the spray badly distributed, the CV will have unacceptably higher values $(15 \%$ or higher).

Measurements were done using a specific device developed by Sawa et al. [24] and Parafiniuk [25] and it was built according to International Organization for Standardization (ISO) 5682-1 [26]. This device (Figure 3) has a 2.5-m-wide table (with slope $5^{\circ}$ ) and consists of 50 " $\mathrm{V}$ "-shaped grooves with the diameter of each trough being $5 \mathrm{~cm}$. The water collected in these groves is directed to graduated tubes that have solenoid valves on the bottoms. In testing, nozzles are positioned on a disc that is able to hold multiple nozzles. Water is circulated on a closed cycle on this device due to the pump, tank, and pipes connecting the different parts. At the time of testing, the temperature of the liquid and air in the laboratory was between 10 and $25{ }^{\circ} \mathrm{C}$ and the relative humidity was less than $50 \%$.
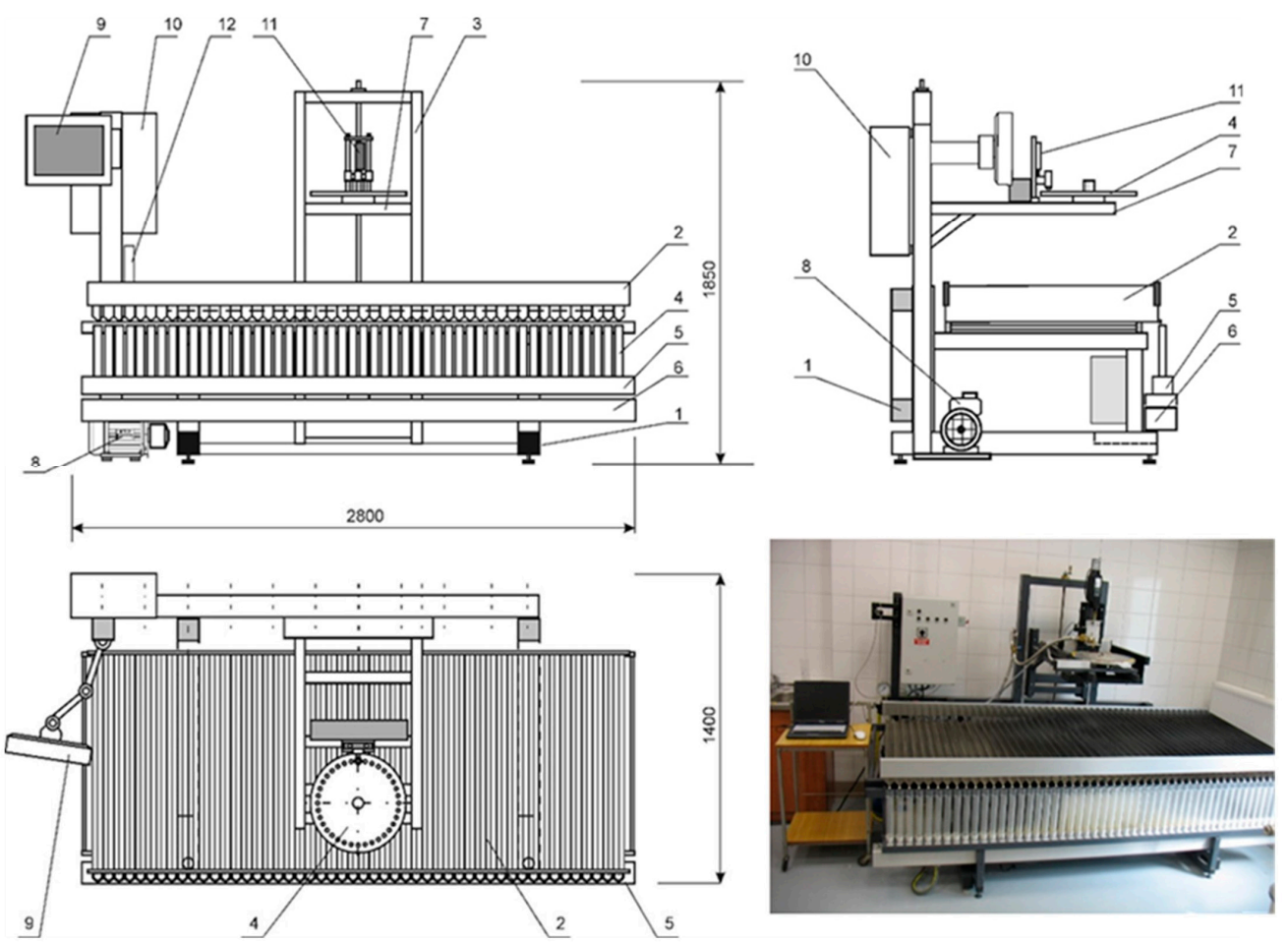

Figure 3. Individual spray distribution device (the dimensions are in millimeters): 1 -device structure, 2-groove table, 3-mechanism of adjusting the nozzle disc height, 4-measuring tubes, 5-assembly of measuring electronics, 6-tank for collecting water, 7-nozzle disc, 8-pump, 9-computer, 10control box, 11—connector, 12-hydraulic assembly [25].

All measurements were carried out with the help of remote software to test multiple nozzles, with results in the form of tables and graphs. In the test, the nozzles were sprayed at a height of $50 \mathrm{~cm}$ height above the device table for one minute, which is enough to get a sufficient amount of water for measurement.

\subsection{Data Analysis}

The regression analysis between the wear time and the flow rate was conducted using Microsoft Excel to find the best model (depending on the coefficient of determination) to fit the relationship. The measurement of the spray distribution was done for individual nozzles; then, by using software from R program ( $R$ Development Core Team [27]), the nozzle data (six nozzles) were combined and converted to obtain a virtual coefficient of variation $\left(C V_{V}\right)$. The $C V_{V}$ is the coefficient of variation $(C V)$ for the virtual transverse spray distribution of the boom and is obtained by combining the results of multiple individual nozzle spray distribution patterns. 


\section{Results}

To determine whether a certain nozzle is worn out, the wear rate for the nozzle must be less than $10 \%$ according to the threshold specified by ISO 16122-2 [23]. If the measured wear rate of the nozzle exceeds this threshold, then it needs to be replaced by the operator or by the sprayer inspector during periodic inspection. Table 2 shows the wear rate (\%) for the three types of nozzles; they did not exceed the $10 \%$ threshold during the whole test. The highest wear rate was registered for the DG nozzle after $40 \mathrm{~h}$ of the accelerated wear test, and it was $9.0 \%$.

Table 2. The wear rate (\%) during the different wear periods for the three types of nozzles.

\begin{tabular}{|c|c|c|c|c|c|c|c|c|c|c|}
\hline \multirow{3}{*}{$\begin{array}{c}\text { Nozzle } \\
\text { Type }\end{array}$} & \multicolumn{10}{|c|}{ Hours of Wear, $h$} \\
\hline & 10 & 20 & 30 & 40 & 50 & 60 & 70 & 80 & 90 & 100 \\
\hline & \multicolumn{10}{|c|}{ Wear Rate, \% } \\
\hline $\mathrm{TT}$ & 3.2 & 4.2 & 5.2 & 6.2 & 5.8 & 5.6 & 6.2 & 6.2 & 6.6 & 7.4 \\
\hline TTj60 & 2.1 & 0.9 & 1.0 & 0.5 & 0.1 & -0.4 & 0.4 & 0.7 & 0.7 & 0.5 \\
\hline DG & 3.7 & 4.9 & 7.1 & 9.0 & 7.8 & 6.5 & 7.8 & 6.7 & 7.3 & 8.3 \\
\hline
\end{tabular}

The TTj60 nozzle had a negative value of wear rate after $60 \mathrm{~h}$ of wear; this was because the measured flow rate at this time was less than the nominal value. The reason for this phenomenon is not yet known.

The flow rates for the TT, TTj60, and DG nozzles during the wear test intervals as measured using 3.0 bar pressure, are presented in Figure 4. The TT and DG nozzles showed a progressive increase in flow rate during the first $50 \mathrm{~h}$ of wear, while the TTj60 nozzle showed a progressive decrease in flow rate. Regression analysis was conducted considering the hours of wear as a predictor and the flow rate as the response. Several models' orders were investigated for each nozzle type considering the coefficient of determination $\left(\mathrm{R}^{2}\right)$ of the model as a criterion to determine the best model. Three models were selected to predict the flow rate based on the hours of wear-one model for each type of nozzle. A 3rd-order model was obtained for the DG nozzle type, where $\mathrm{R}^{2}$ was 0.54 , and a 5 th-order model for the TT nozzle type, where $\mathrm{R}^{2}$ was 0.76 . A $2^{\text {nd }}$-order model for the TTj60 nozzle type had a low $\mathrm{R}^{2}(0.31)$. These models did not show significant prediction as shown in Figure 4 .

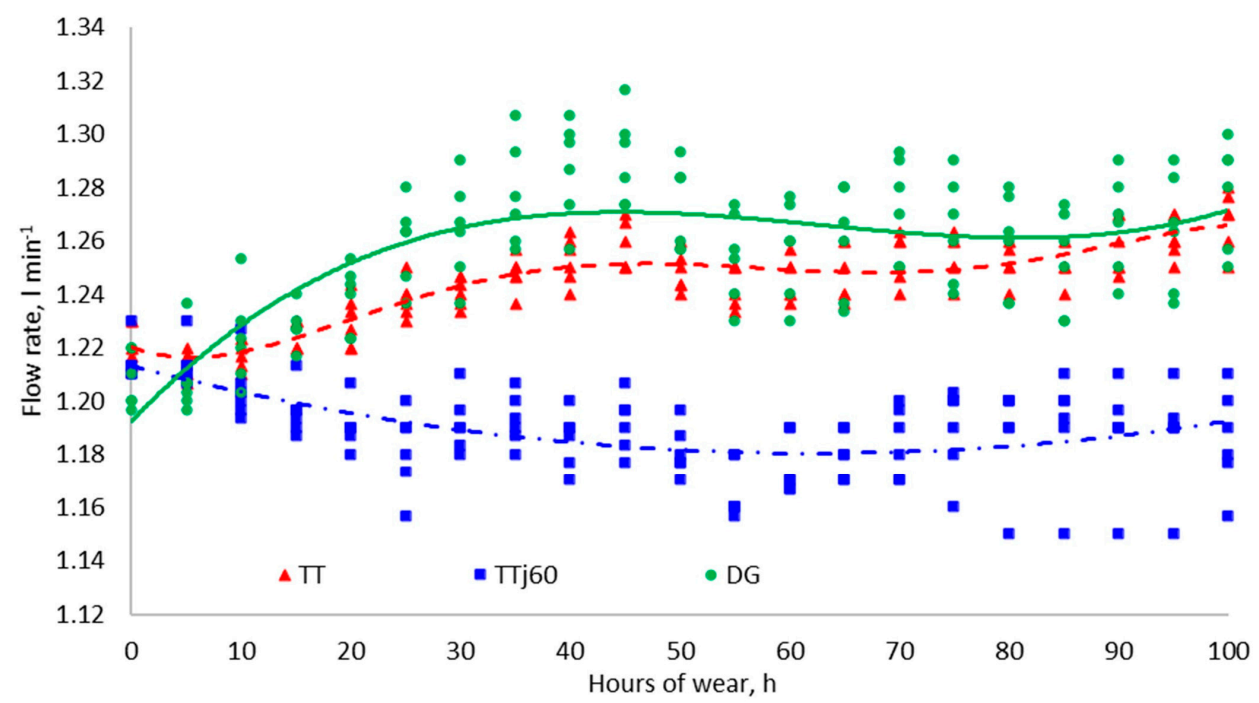

Figure 4. Flow rate at different wear intervals for the TT, TTj60, and DG nozzles.

After analysis of the changes in nozzle structure with visual methods (Figure 5), it was not possible to notice changes in the dimensions of the nozzle orifice. It is worth 
mentioning that these photos were taken for the pre-orifice from inside the nozzle body. It was not possible to take such photos for the final orifice from outside because of the geometry of these nozzles, especially the TT and TTj60 nozzles where the final orifice from outside is almost hidden.

a)
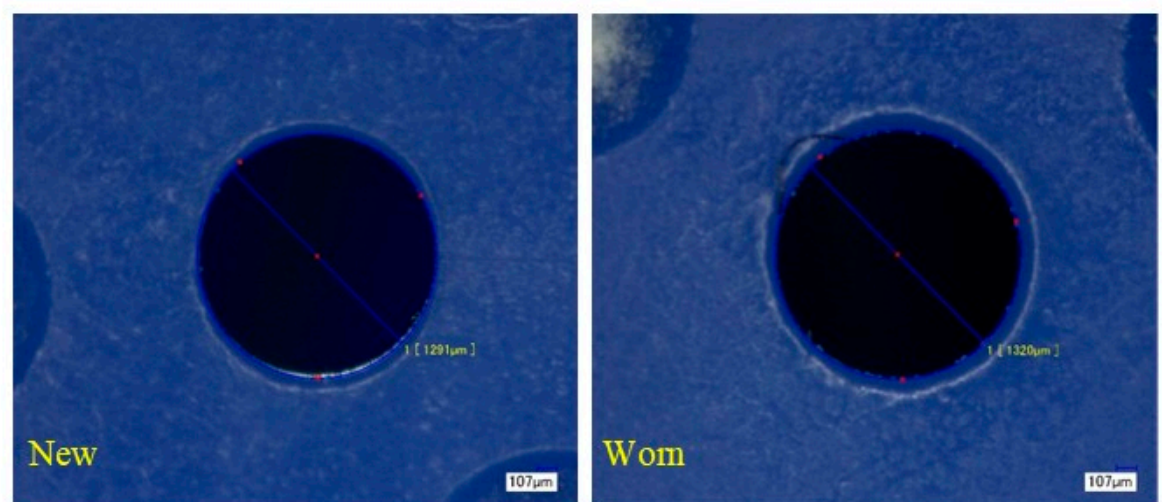

b)
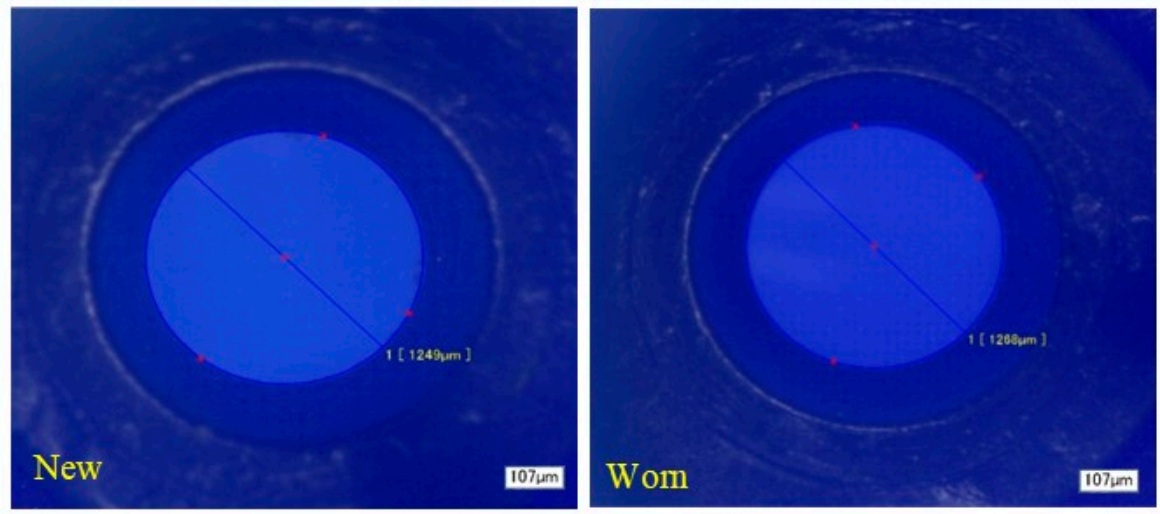

c)
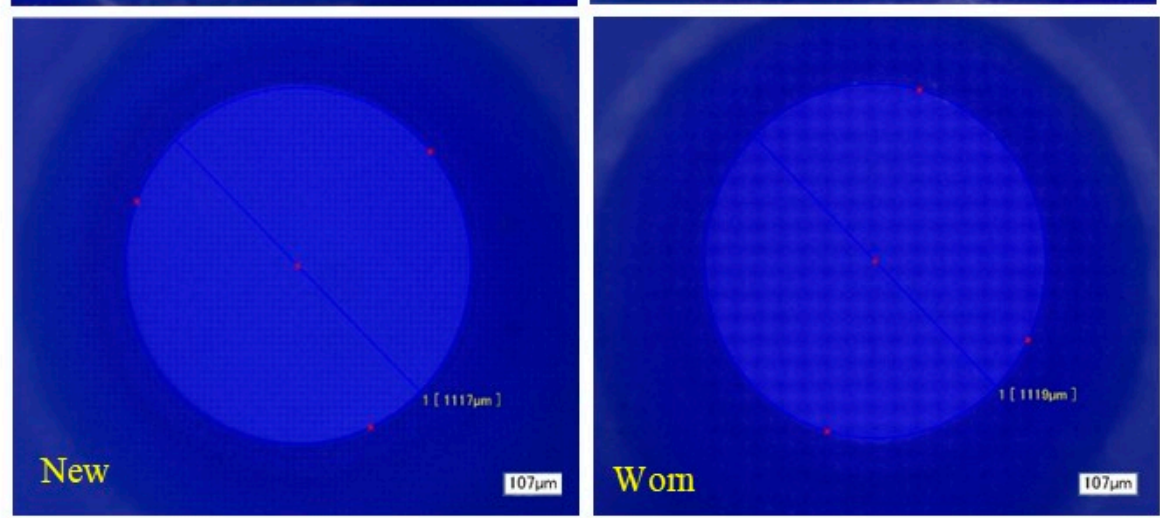

Figure 5. Photographs of the nozzle pre-orifice (from inside the nozzle body) before (New) and after the accelerated wear test (Worn): (a) DG nozzle, (b) TT nozzle, (c) TTj60 nozzle.

Further investigation was done by measuring the area and diameter of the nozzle orifice by taking photos of the nozzle orifice (Table 3). The dimensions (area and diameter) of the TT and DG nozzles increased after finishing the accelerated wear test, whereas there were no changes in the area and diameter of the TTj60 nozzle orifice after finishing the accelerated wear test. The obtained results were probably caused by two factors. Firstly, the effect of the pre-orifice nozzle design may reduce the pressure inside the second chamber (between the pre-orifice and final orifice). This reduction in liquid pressure reduced the flow energy of this liquid and then could affect the wear process of the nozzle orifice. Secondly, the TTj60 nozzle has two final exits; this probably reduced the liquid pressure further and reduced its effect compared with the TT and DG nozzles, which both have 
only one exit orifice. The results of the nozzle orifice dimensions could explain the higher resistance of the TTj60 nozzle to wear compared with the TT and DG nozzles.

Table 3. Orifice area and diameter for the DG, TT, and TTj60 nozzles before (New) and after finishing the accelerated wear test (Worn).

\begin{tabular}{ccccccc}
\hline & \multicolumn{2}{c}{ DG } & \multicolumn{2}{c}{ TT } & \multicolumn{2}{c}{ TTj60 } \\
& New & Worn & New & Worn & New & Worn \\
\hline Area, $\mathrm{mm}^{2}$ & 1.31 & 1.37 & 1.23 & 1.26 & 0.98 & 0.98 \\
Diameter, $\mathrm{mm}$ & 1.29 & 1.32 & 1.25 & 1.27 & 1.12 & 1.12 \\
\hline
\end{tabular}

Agricultural nozzles can be classified according to size (discharge rate), which represents the nominal flow rate of these nozzles, and are given a certain color for each nozzle according to the size. As the TTj60 nozzle is the same size (nominal flow rate is $1.18 \mathrm{~L} / \mathrm{min}$ ) as the TT and DG nozzles but with double orifices, these TTj60 nozzle double orifices must be smaller in dimension. This leads to a question whether the size (or the nominal flow rate) of the TTj60 nozzle has an effect on the wear behavior of such a nozzle. This question could be answered by further studies on this type of nozzle (TTj60) of different sizes and possibly of different materials.

The results for the virtual coefficient of variation $\left(\mathrm{CV}_{\mathrm{V}}\right)$ in Table 4 show that the spray distribution of the nozzles set for every nozzle type after finishing the acceleration test was within the allowed threshold ( $\mathrm{CV}_{\mathrm{V}}$ values under $\left.10 \%\right)$ set by ISO 16122-2 [23]. However, a few values were higher than $10 \% \mathrm{CV}_{\mathrm{V}}$ during certain test periods for the tested nozzle types. For example, the $\mathrm{CV}_{\mathrm{V}}$ exceeded the $10 \%$ allowed limit for the TT nozzle after 40, 60, 80 , and $90 \mathrm{~h}$ of wear. This was noticed for the TTj60 nozzle only after 80 and $90 \mathrm{~h}$ of wear, but then it decreased again to the allowed limit after $100 \mathrm{~h}$ of wear (9\%). The allowed limit for $\mathrm{CV}_{\mathrm{V}}$ was exceeded for the DG nozzle only in the middle of the wear test (after $40 \mathrm{~h}$ of wear); the registered value was $11 \%$.

Table 4. The spray distribution characteristics at different wear intervals for the TT, TTj60, and DG nozzles.

\begin{tabular}{|c|c|c|c|c|c|c|c|c|c|c|c|c|}
\hline \multirow{2}{*}{$\begin{array}{l}\text { Nozzle } \\
\text { Type }\end{array}$} & \multirow{2}{*}{$\begin{array}{l}\text { Spray Distribution } \\
\text { Characteristics }\end{array}$} & \multicolumn{11}{|c|}{ Hours of Wear, $h$} \\
\hline & & 0 & 10 & 20 & 30 & 40 & 50 & 60 & 70 & 80 & 90 & 100 \\
\hline \multirow{3}{*}{$\mathrm{TT}$} & Average ${ }^{*}, \mathrm{~mL}$ & 193.3 & 200.7 & 199.5 & 210.1 & 194.0 & 196.5 & 199.8 & 208.1 & 215.4 & 214.5 & 218.5 \\
\hline & $\mathrm{SD} * *$ & 7.1 & 6.6 & 12.5 & 7.6 & 20.6 & 14.7 & 22.4 & 11.4 & 28.5 & 21.3 & 15.1 \\
\hline & $\mathrm{CV}_{\mathrm{V}}$ & $4 \%$ & $3 \%$ & $6 \%$ & $4 \%$ & $11 \%$ & $8 \%$ & $11 \%$ & $6 \%$ & $13 \%$ & $10 \%$ & $7 \%$ \\
\hline \multirow{3}{*}{ TTj60 } & Average, mL & 196.1 & 202.7 & 193.6 & 203.7 & 194.1 & 191.2 & 195.0 & 198.1 & 200.7 & 206.5 & 206.6 \\
\hline & $\mathrm{SD}$ & 11.5 & 10.9 & 7.0 & 8.8 & 15.4 & 15.2 & 13.9 & 11.8 & 24.8 & 21.2 & 18.8 \\
\hline & $\mathrm{CV}_{\mathrm{V}}$ & $6 \%$ & $5 \%$ & $4 \%$ & $4 \%$ & $8 \%$ & $8 \%$ & $7 \%$ & $6 \%$ & $12 \%$ & $10 \%$ & $9 \%$ \\
\hline \multirow{3}{*}{ DG } & Average, $\mathrm{mL}$ & 213.2 & 211.8 & 213.4 & 220.7 & 215.0 & 212.5 & 216.4 & 213.3 & 211.4 & 222.9 & 227.1 \\
\hline & $\mathrm{SD}$ & 8.1 & 13.5 & 13.5 & 11.6 & 23.3 & 18.3 & 18.9 & 14.0 & 15.5 & 12.6 & 11.9 \\
\hline & $\mathrm{CV}_{\mathrm{V}}$ & $4 \%$ & $6 \%$ & $6 \%$ & $5 \%$ & $11 \%$ & $9 \%$ & $9 \%$ & $7 \%$ & $7 \%$ & $6 \%$ & $5 \%$ \\
\hline
\end{tabular}

* Average value of the water quantity collected in every patternator vessel (virtual $10 \mathrm{~cm}$ width) of the spray swath. ${ }^{* *}$ Standard deviation of the values of spray quantity collected in the patternator vessels.

For better visualization, only a few positions of the spray swath (patternator width) and only selected wear intervals were considered in Figure 6a-c. The intent was to show the change in the spray distribution in a certain position during the wear periods of the TT, TTj60, and DG nozzles. The X-axis in this figure represents the position of the graduated tubes that were used in the patternator table. The numbers on this axis refer to the tube position starting from the left to the right of the table. As mentioned above, not all the fifty positions on this axis are shown in this figure. Instead, only chosen positions with five tubes intervals were included. The Y-axis represents the quantity of water $(\mathrm{ml})$ collected in each tube along the patternator table. We did not observe a clear trend of the changes in the spray distribution during the different wear periods. However, we saw that the spray 
quantity collected in the middle vessels increased as the wear test progressed for the three types of nozzles, and this is in agreement with results of Bolat et al. [28].

a)

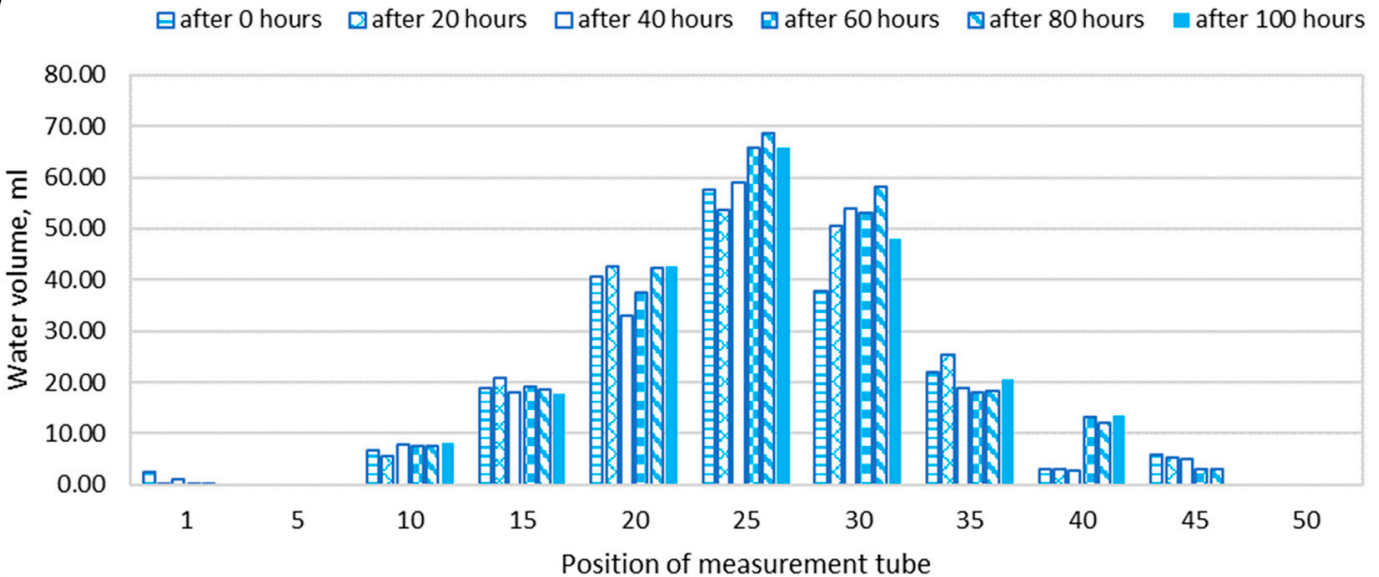

b)

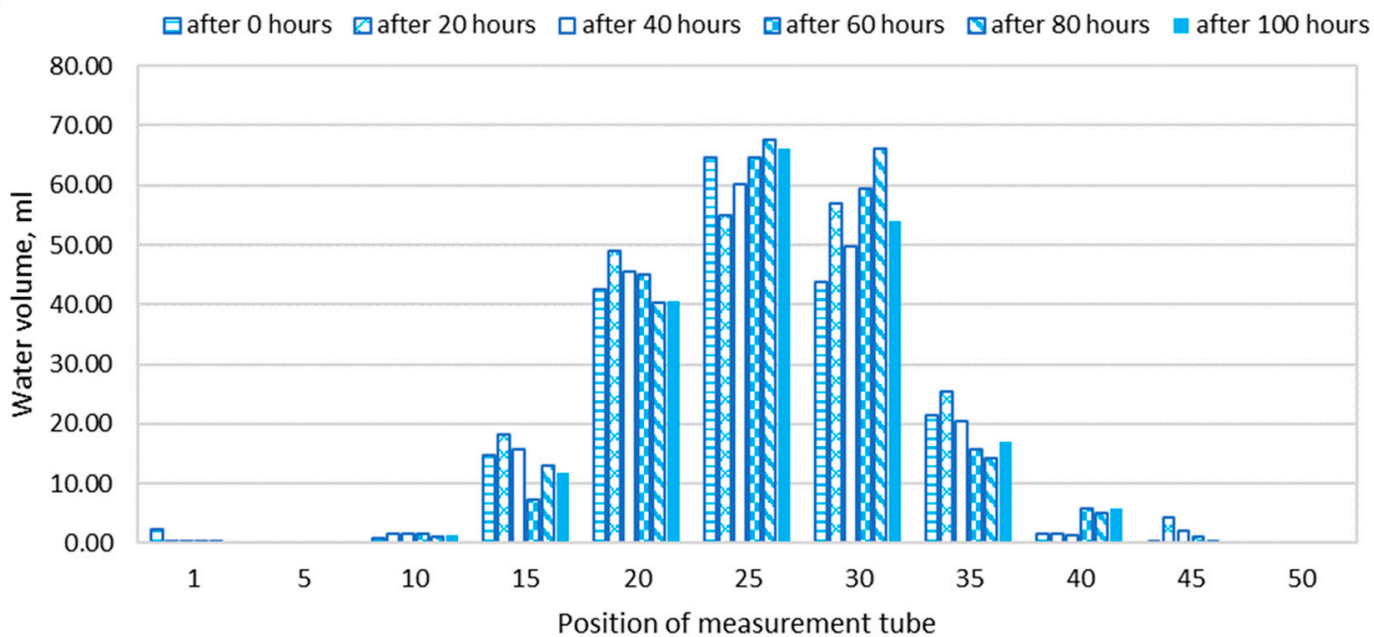

c)

$\square$ after 0 hours $\square$ after 20 hours $\square$ after 40 hours $\square$ after 60 hours $\square$ after 80 hours $\square$ after 100 hours

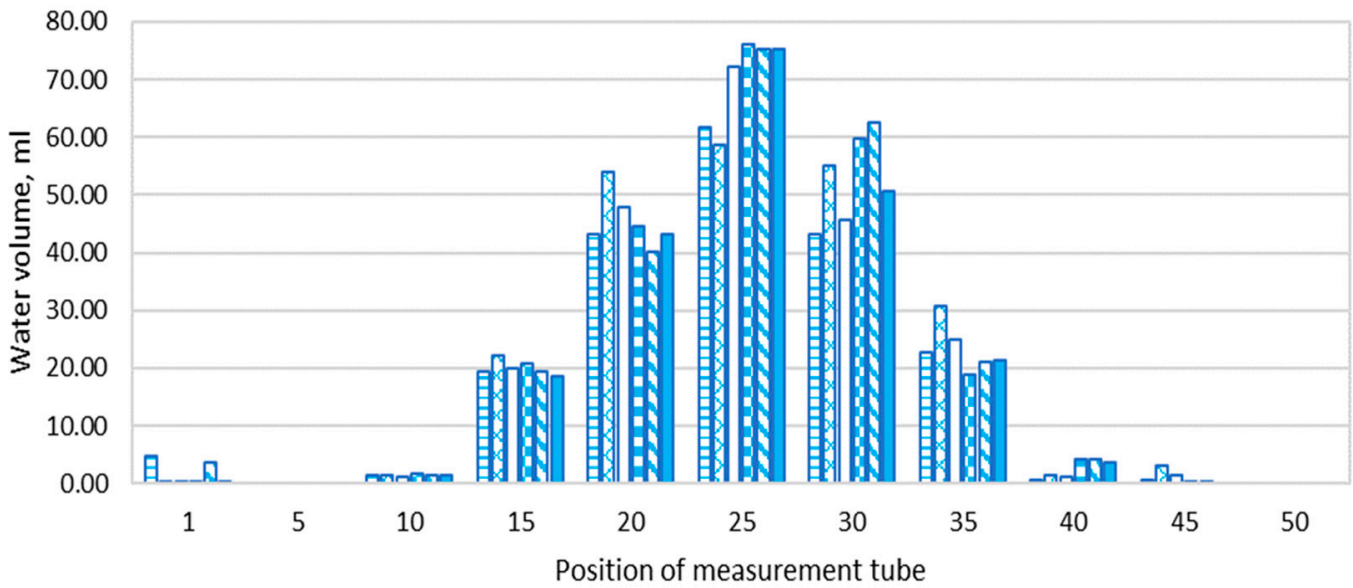

Figure 6. Spray distribution of various nozzles during different wear hours: (a) TT, (b) TTj60, (c) DG.

A comparison between the three types nozzles (TT, TTj60, and DG) of the spray distribution under the patternator width during the wear periods of zero (new nozzles), 50 $h$, and $100 \mathrm{~h}$ is shown in Figure $7 \mathrm{a}-\mathrm{c}$, respectively. The $\mathrm{X}$ - and $\mathrm{Y}$-axes represent the same information as in the previous figure. However, all of the measurement positions on the 
$\mathrm{X}$-axis were included in this figure to show the smoothness of the spray pattern along the spray swath.

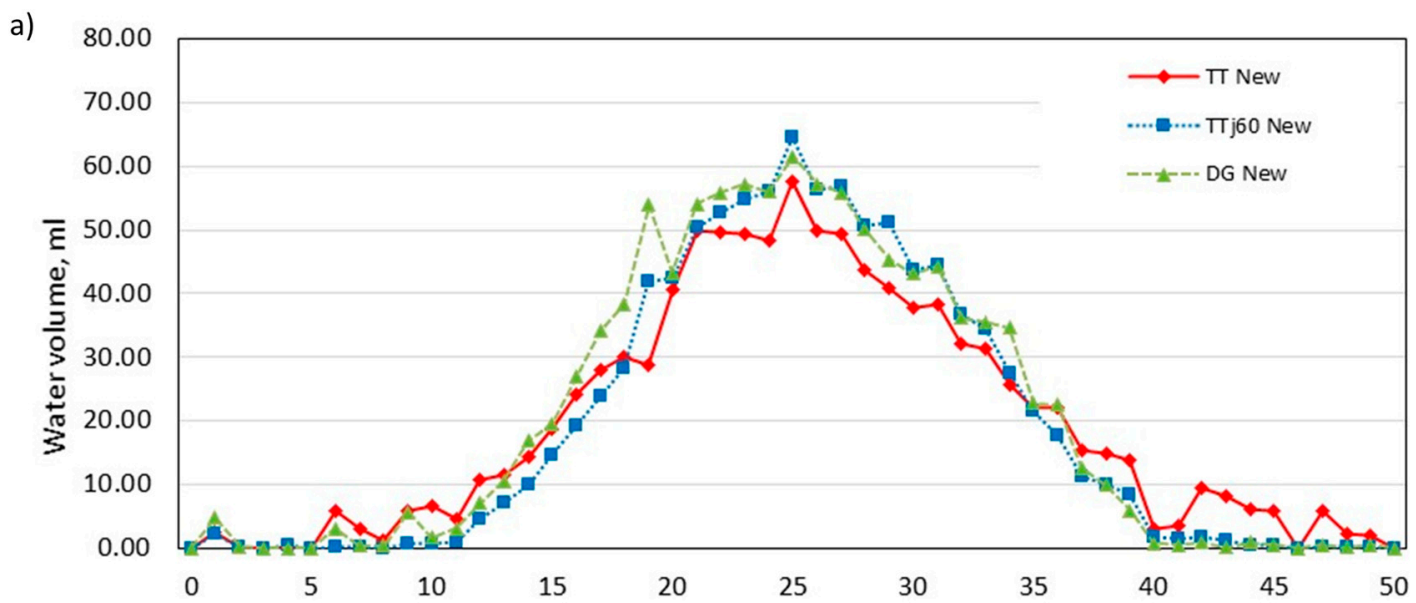

b)

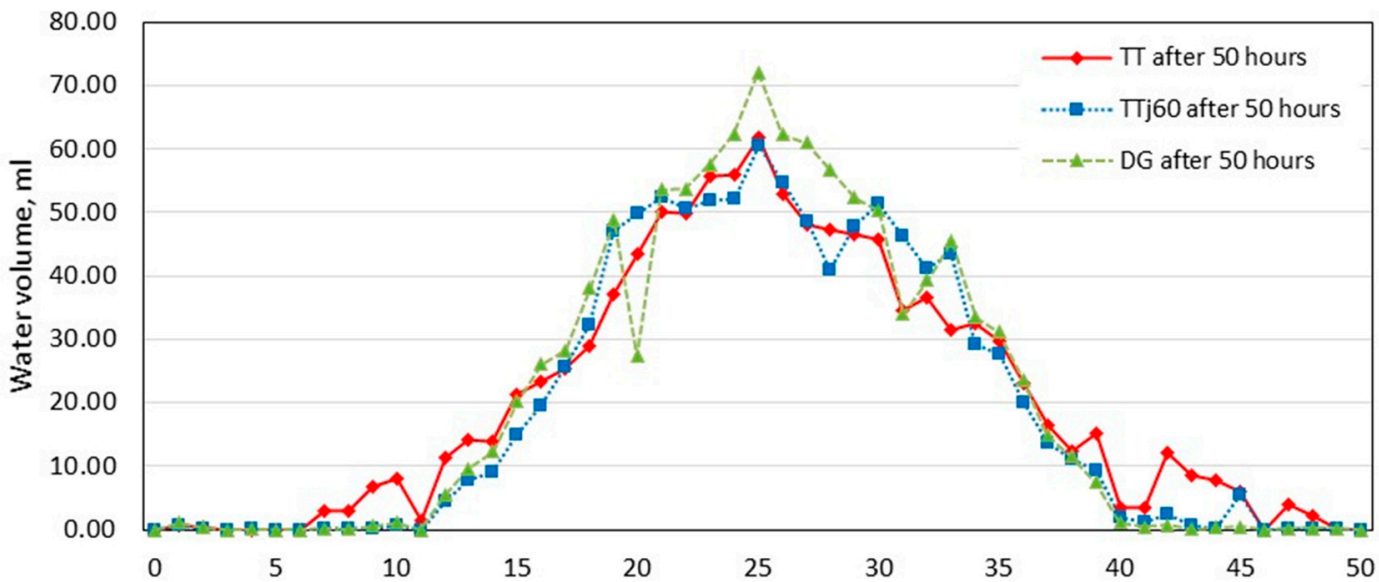

c)

Position of measurment tube

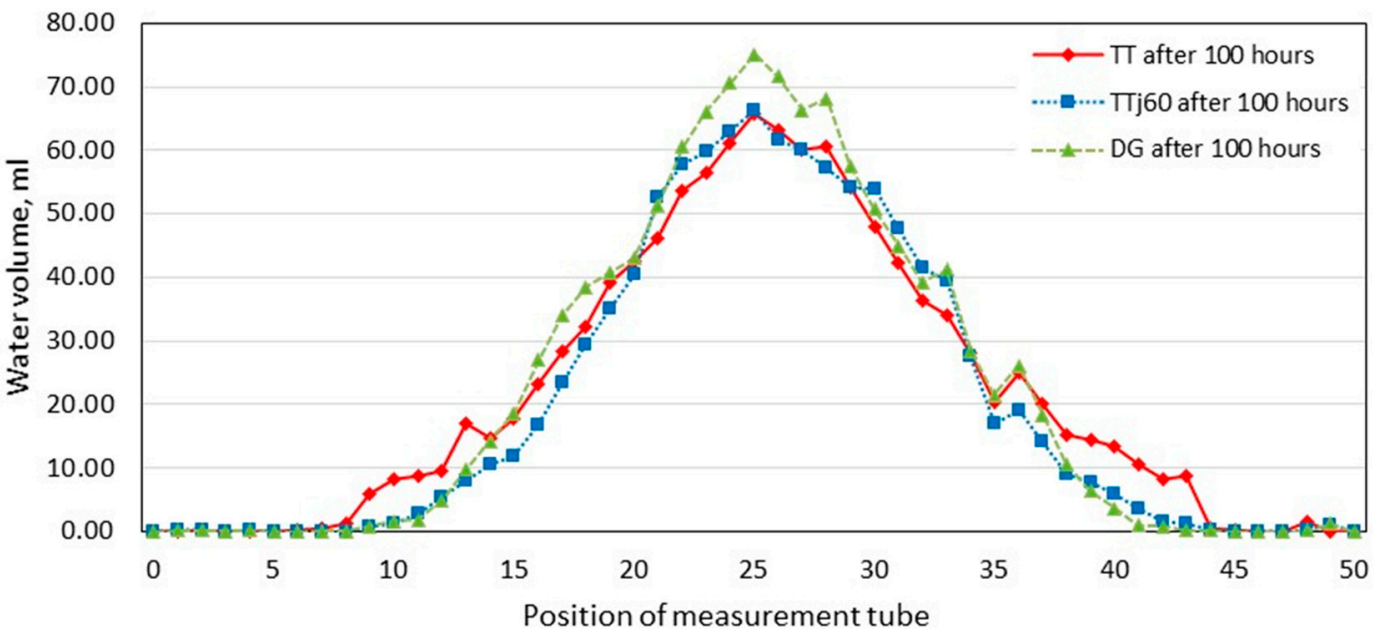

Figure 7. Spray distribution of the TT, TTj60, and DG nozzles before the wear test: (a) new nozzles, (b) after $50 \mathrm{~h}$, (c) after $100 \mathrm{~h}$.

There was a higher quantity of spray that accumulated in the middle positions of the patternator when the DG nozzle proceeded with the wear test as compared with the behavior of TT and TTj60. The latter two nozzles had similar behavior during the wear test and they sprayed more quantity of water after $100 \mathrm{~h}$ of wear. We also noticed from the 
obtained figure that the spray patterns for the three nozzle types became smoother as the wear test proceeded. This means that the $C_{V}$ values decreased towards the end of the test. This effect was confirmed upon a review of Table 4 , which shows that the $C_{V}$ values decreased after $100 \mathrm{~h}$ of wear.

The spray distribution results for individual nozzles in Figures 6 and 7 indicate that although there was a distortion in the middle of the spray pattern after the accelerated wear test, this did not affect the homogeneity of the spray pattern for the whole nozzles if they were virtually assembled in a sprayer boom. This was confirmed by the values of $\mathrm{CV}_{\mathrm{v}}$, which were within the allowed values indicated by the sprayer inspection standard.

\section{Conclusions}

Based on the results of this research, the following can be concluded:

1. The TTj60 nozzle type showed the highest resistance to wear, followed by the TT type and DG. The wear rate of the TTj60 nozzle after finishing the accelerated wear test was $0.5 \%$, while it was $7.4 \%$ and $8.3 \%$ for the TT and DG nozzles, respectively.

2. During the first $45 \mathrm{~h}$ of wear, the flow rates of the DG and the TT nozzles increased with the wear period, while the flow rate of the TTj60 nozzle showed an opposite trend. The increase in flow rate for the DG nozzle was from $1.21 \mathrm{~L} / \mathrm{min}$ for new nozzles to $1.29 \mathrm{~L} / \mathrm{min}$ after $45 \mathrm{~h}$ of wear and from $1.22 \mathrm{~L} / \mathrm{min}$ to $1.26 \mathrm{~L} / \mathrm{min}$ for the TT nozzle. For the new TTj60 nozzle, the flow rate was $1.21 \mathrm{~L} / \mathrm{min}$, and it was 1.19 $\mathrm{L} / \mathrm{min}$ after $45 \mathrm{~h}$ of wear.

3. After completing the test, the virtual coefficient of variation $\left(\mathrm{CV}_{\mathrm{v}}\right)$ values for the three types of nozzles were less than $10 \%$ (7\%, 9\%, and 5\% for TT, TTj60, and DG, respectively), which is acceptable according to the ISO 16122-2, 2015 standard.

4. There was an increase in the quantity of spray deposited in the middle of the spray swath as the wear test progressed for the three types of nozzles.

Author Contributions: Conceptualization, M.M. and A.S.; methodology, M.M. and S.P.; software, M.M. and A.S.; validation, S.P.; formal analysis, M.M. and A.S.; investigation, M.M. and A.S.; resources, M.M. and A.S.; data curation, M.M., A.S. and S.P.; writing-original draft preparation, M.M. and A.S.; writing-review and editing, A.S. and S.P.; visualization, M.M. and A.S.; supervision, S.P.; project administration, M.M., A.S. and S.P.; funding acquisition, S.P. All authors have read and agreed to the published version of the manuscript.

Funding: Not applicable.

Institutional Review Board Statement: Not applicable.

Informed Consent Statement: Not applicable.

Data Availability Statement: Not applicable.

Conflicts of Interest: The authors declare no conflict of interest.

\section{References}

1. Dafsari, R.A.; Yu, S.; Choi, Y.; Lee, J. Effect of geometrical parameters of air-induction nozzles on droplet characteristics and behaviour. Biosyst. Eng. 2021, 209, 14-29. [CrossRef]

2. Miller, P.C.; Tuck, C.R.; Murphy, S.; Ferreira, M. Measurements of the droplet velocities in sprays produced by different designs of agricultural spray nozzle. In Proceedings of the European Conference on Liquid Atomization and Spray Systems, Como Lake, Italy, 8-10 September 2008; Paper ID ILASS08-8-5. pp. 8-10.

3. Kennelly, M.M.; Wolf, R.E. Effect of nozzle type and water volume on dollar spot control in greens-height creeping bentgrass. Appl. Turfgrass Sci. 2009, 6, 1-8. [CrossRef]

4. Lafferty, C.L.; Tian, L.F. Using computation fluid dynamics to determine the effect of internal nozzle flow on droplet size. In Proceedings of the 2001 ASAE Annual Meeting-American Society of Agricultural and Biological Engineers, Sacramento, CA, USA, 29 July-1 August 2001; p. 1.

5. Vong, C.N.; Larbi, P.A. Development and Prototype Testing of an Agricultural Nozzle Clog Detection Device. Trans. ASABE 2021, 64, 49-61. [CrossRef] 
6. Cerruto, E.; Manetto, G.; Papa, R.; Longo, D. Modelling Spray Pressure Effects on Droplet Size Distribution from Agricultural Nozzles. Appl. Sci. 2021, 11, 9283. [CrossRef]

7. Chen, P.; Lan, Y.; Huang, X.; Qi, H.; Wang, G.; Wang, J.; Wang, L.; Xiao, H. Droplet deposition and control of planthoppers of different nozzles in two-stage rice with a quadrotor unmanned aerial vehicle. Agronomy 2020, 10, 303. [CrossRef]

8. Krawczuk, A.; Parafiniuk, S.; Przywara, A.; Huyghebaert, B.; Rabier, F.; Limbourg, Q.; Mostade, O.; Kocira, S. Technical parameters of biostimulant spraying a determinant of biometric traits and yield of soybean seeds. Agric. Eng. 2021, 25, 171-179. [CrossRef]

9. Yao, W.; Lan, Y.; Hoffmann, W.C.; Li, J.; Guo, S.; Zhang, H.; Wang, J. Droplet size distribution characteristics of aerial nozzles by bell20614 helicopter under medium and low airflow velocity wind tunnel conditions and field verification test. Appl. Sci. 2020, 10, 2179. [CrossRef]

10. Ballal, K.; Krishnan, P.; Kemble, J.; Issler, A. Nozzle selection and replacement based on nozzle wear analysis. In Proceedings of the Third International Conference on Precision Agriculture, Madison, WI, USA, 23-26 June 1996; American Society of Agronomy, Crop Science Society of America, Soil Science Society of America: Madison, WI, USA, 1996; pp. 795-804.

11. Forney, S.H.; Luck, J.D.; Kocher, M.F.; Pitla, S.K. Laboratory and full boom-based investigation of nozzle setup error effects on flow, pressure, and spray pattern distribution. Appl. Eng. Agric. 2017, 33, 641-653. [CrossRef]

12. Krishnan, P.; Evans, T.; Ballal, K.; Kemble, L.J. Scanning electron microscopic studies of new and used fan nozzles for agricultural sprayers. Appl. Eng. Agric. 2004, 20, 133-138. [CrossRef]

13. Singh, A.K.; Bhatt, Y.C. Wear on circular orifice plate of hollow-cone type agrochemical spray nozzles. Agric. Eng. Int. CIGR J. 2018, 20, 78-84.

14. Singh, A.K.; Bhatt, Y.C.; Dhande, K.; Wandkar., S.V.; Stanley, N. System of mathematical equations to predict wear rate on circular-cone orifice of pesticide spray nozzles. Int. J. Precis. Agric. Aviat. 2019, 2, 76-80.

15. Bochniak, A.; Kluza, P.A.; Kuna-Broniowska, I.; Koszel, M. Application of non-parametric bootstrap confidence intervals for evaluation of the expected value of the droplet stain diameter following the spraying process. Sustainability 2019, 11, 7037. [CrossRef]

16. Sayinci, B. Detection of shape manufacturing defects of flat fan-pattern nozzle orifices using elliptic fourier descriptors. J. Agric. Sci. 2016, 22, 317-330.

17. Kluza, P.A.; Kuna-Broniowska, I.; Parafiniuk, S. Modeling and prediction of the uniformity of spray liquid coverage from flat fan spray nozzles. Sustainability 2019, 11, 6716. [CrossRef]

18. Sayinci, B. Effect of strainer type, spray pressure, and orifice size on the discharge coefficient of standard flat-fan nozzles. Turk. J. Agric. For. 2015, 39, 692-704. [CrossRef]

19. Matthews, G. Chapter 3: Application of pesticides. In Pesticides: Health, Safety and the Environment; John Wiley \& Sons: Hoboken, NJ, USA, 2015; pp. 46-77.

20. ASAE S471; Procedure for Measuring Sprayer Nozzle Wear Rate. 46th ed. ASAE Standards: St. Joseph, MI, USA, 1999.

21. Huyghebaert, B. Verification of Measurement Methods of Flat Fan Nozzles Working Parameters Used in Agriculture. Ph.D. Thesis, University of Life Sciences in Lublin, Lublin, Poland, 2015; p. 149.

22. Huyghebaert, B.; Debouche, C.; Mostade, O. Flow rate quality of new flat fan nozzles. Trans. ASAE 2001, 44, 769. [CrossRef]

23. ISO 16122-2; Agricultural and Forestry Machinery-Inspection of Sprayers in Use-Part 2: Horizontal Boom Sprayers. International Organization for Standardization: Geneva, Switzerland, 2015; p. 18.

24. Sawa, J.; Huyghebaert, B.; Parafiniuk, S. Testing device for a complex measurement of the performances nozzles. In Proceedings of the 4th European Workshop on Plant Protection Equipment Inspections-SPISE 4 Workshop, Lana, South Tyrol, Italy, 27-29 March 2012; pp. 228-233.

25. Parafiniuk, S. Conversion of Test Results Obtained for Single Spray Nozzles to Identify the Working Parameters of the Sprayer Boom. Ph.D. Habilitation Thesis, University of Life Sciences in Lublin, Lublin, Poland, 2013.

26. ISO 5682-1; Equipment for Crop Protection-Spraying Equipment-Part 1: Test Methods for Sprayer Nozzles. International Organization for Standardization: Geneva, Switzerland, 1996; p. 18.

27. R Development Core Team. R: A Language and Environment for Statistical Computing; R Foundation for Statistical Computing: Vienna, Austria, 2012; ISBN 3-900051-07-0. Available online: http:/ / www.R-project.org/ (accessed on 20 September 2021).

28. Bolat, A.; Ozluoymak, O.B.; Bayat, A. Determination of spray performance of new and worn flat fan nozzles and spray angle based on novel image analysis software. Fresenius Environ. Bull. 2021, 30, 8532-8540. 